\title{
TECHNICAL PROBLEMS IN METABOLIC INVESTIGATIONS IN CHILDHOOD
}

BY

\author{
MARGARET E. EDMUNDS*
}

From the Institute of Child Health (University of London), The Hospital for Sick Children

(Received for Publication november 23, 1949)

The great difficulty encountered in obtaining accurate collections of faeces and urine from young children is common knowledge to all those engaged in metabolic investigation on these subjects. It was therefore thought worth while recording the methods that we have found most satisfactory to date.

\section{Problems of Collection}

While older children present no greater problem than adults, in that they will cooperate fully in making the required collections, younger children are unreliable and require special appliances.

The most generally useful of these is the metabolic bed. Various types of such a bed have been described (Bendix, 1896; Bendix and Finkelstein, 1900; Schabad, 1908; Talbot, 1909; Du Bois, 1911; Howland and Cooke, 1911; Hoobler, 1912; Gerstley, 1930; Hoag, 1932) and others all write of

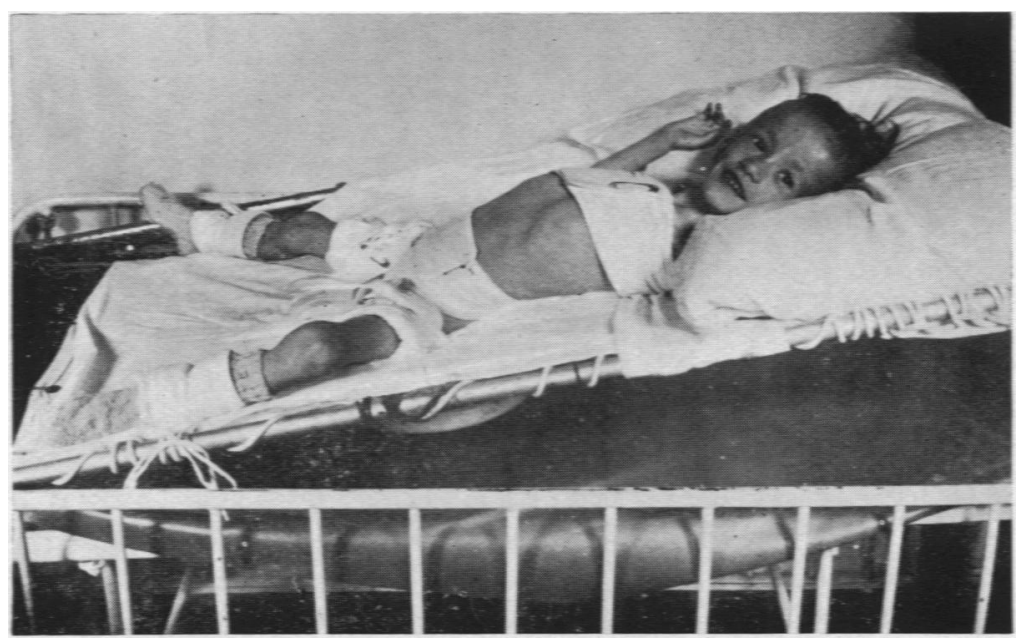

Plate I.

* Cow and Gate Research Fellow. metabolic beds. These beds differ widely in construction and detail, but the principle of all of them, and of the one described below, is the same. The latter was devised because the materials used were easily obtainable and it could be made in the hospital. The basic idea was taken from the metabolic bed used at the Belle Vue Hospital, New York. It was made from an old empyema frame, appropriate holes being cut for faeces and urine to pass through into suitable receptacles placed below. In the case of the urine, this was made possible by using a glass urinal which was connected by rubber tubing to a bottle placed underneath the cot.

\section{The Metabolic Bed}

The bed with a child lying in it is illustrated in Plate $I$. There should be a round hole 5 in. in diameter about two-thirds of the way from the head of the frame (Fig. 1). (It is advisable to strengthen the canvas round this by lines of machine stitching and over-sewing the edge.) A slit 4 in. long and 2 in. wide is made in the midline below the round hole, and separated from it by about 2 in. Similar holes to correspond must be made in the sheets used. The frame is placed on the cot in a sloping position, the upper end resting in the sockets for the half-way position of the cot sides, and the lower end resting on the springs. The mattress is not used.

The child is placed so that the buttocks rest in the round hole. It is maintained in this position by a flannel binder. This consists of two double-thickness strips of flannel stitched together in the middle by two transverse, parallel lines of stitching (Fig. 2). The shorter strip ( $2 \mathrm{ft} .3$ in. $\times 5$ in.) is uppermost and the ends are pinned round the child. The 


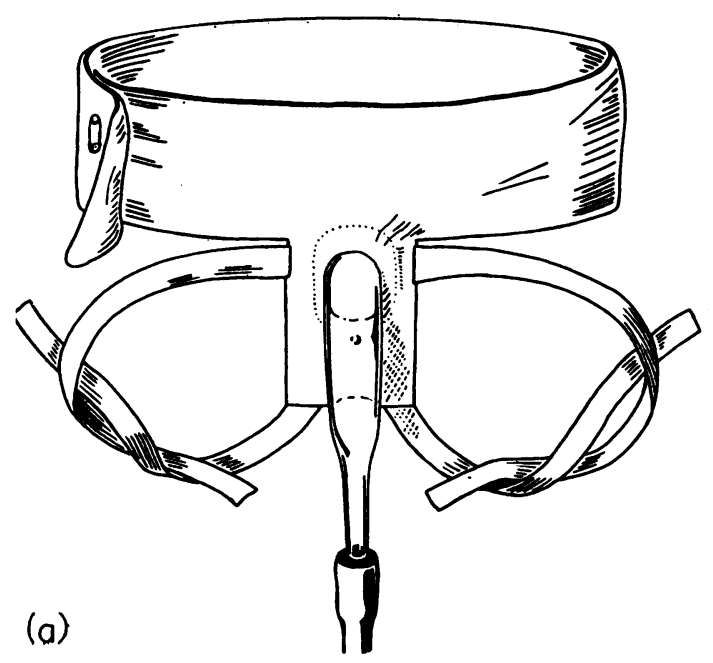

(b)

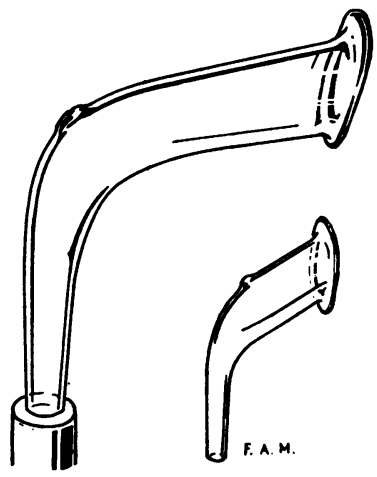

Fig. 2.

Plate. I-Photograph showing a child lying in the metabolic bed.

Fig. 1.-Diagram showing the canvas frame in detail, the hole for the child's buttocks, and binders to hold the child to the frame.

FIG. 2a.-Flannel binder and attachment to which is affixed the urinal (Figs. $2 b$ and 2c.)

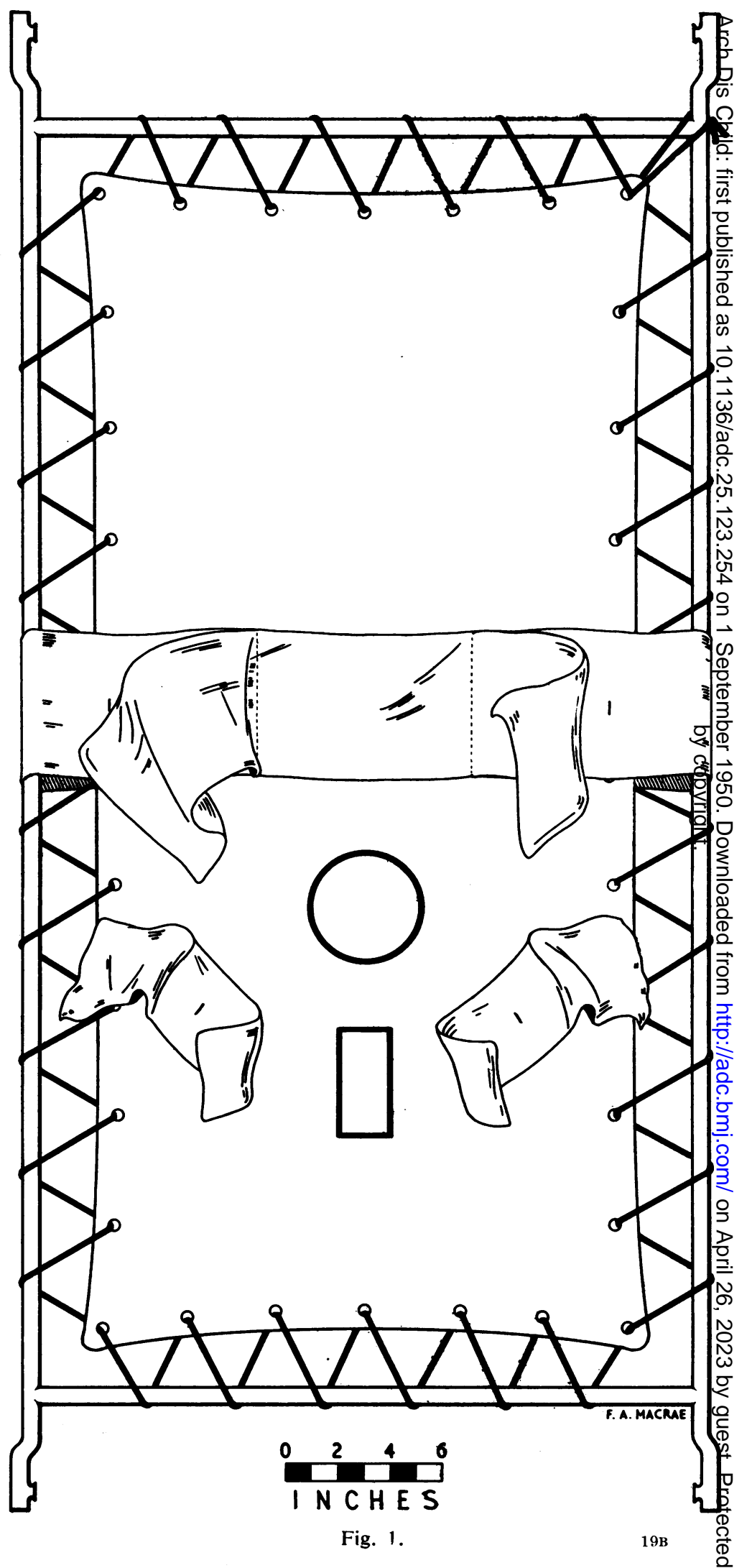


longer strip ( $5 \mathrm{ft} . \times 6 \frac{1}{2}$ in.) is next to the canvas and the ends are folded over the sides of the frame at the appropriate level and pinned on the underside.

Two small binders are pinned on the canvas (from the underside) on either side of the hole and the ends pinned round the thighs so as to hold them in abduction. The leg below the knee can be free or, if necessary, may be fixed as in Plate $I$.

A glass urinal $8 \frac{1}{2}$ in. long and $1 \frac{1}{4}$ in. diameter (Fig. 2b) is slipped over the penis, and held in place by a fourth, specially designed, binder (Fig. 2a). This consists of a strip of flannel $2 \mathrm{ft}$. $\times 4 \mathrm{in}$. which is pinned round the child's pelvis. It has in front a miniature 'apron' with a hole in it exactly fitting the urinal below the flange. There are two narrow strips on either side of the ' apron' which tie round each thigh.

An enamel bowl, or a bedpan, is placed underneath the buttocks to receive the faeces. The urinal is connected by rubber tubing to a bottle under the cot.

There are several disadvantages in this method, the greatest of which is the degree of immobilization involved. It does not seem to occasion any discomfort in itself, and the arms are free and, when permissible, the legs below the knee, yet as it may have to be used for days on end it is bound to become irksome to the patient. The skin is apt to become sore in some patients where the buttocks press against the edge of the hole, although this can usually be prevented by tight lashing of the canvas to the frame to prevent sagging; also the child cannot sit up.

No modification has yet been found to make the method suitable for girls (although we are still hoping to do this).

Apart from these objections the apparatus is entirely efficient, there being no leakage. The only risk of loss is during washing and weighing, which should be accomplished as rapidly as possible. A child of any age can be nursed on it up to that age at which such appliances are unnecessary. In some toddlers it has been found useful at night, when incontinence is more likely, even when it is not required by day.

For premature and marasmic infants, who should be nursed on their sides, with frequent changes of position, the metabolic bed is unsuitable, although Gordon, Levine, Wheatley, and Marples (1937), Levine, Gordon, and Marples (1941), and Levine, Dann, and Marples (1943) apparently used a modification of Hoag's apparatus for these patients. Schloss and Crawford (1911) devised a method in which the glass tube was held over the penis by adhesive tape stuck on to knitting wool which had been wound round the body. The faeces were collected in a rubber napkin and washed off with a known quantity of water. Coulson and Stewart (1946) fastened a rubber tube over the penis with adhesive tape. The objection to both of these methods is the adhesive tape, which rapidly damages a fragile skin, and fails to stick if it becomes damp. Thomson (1944) used rubber aural syringes held on with straps. Numerous attempts were made to use this method, especially as it was the only method encountered which could be used for girls, but no system of straps could be found which was tight enough to be efficient, and yet did not cause oedema and excoriation. For a study in premature infants

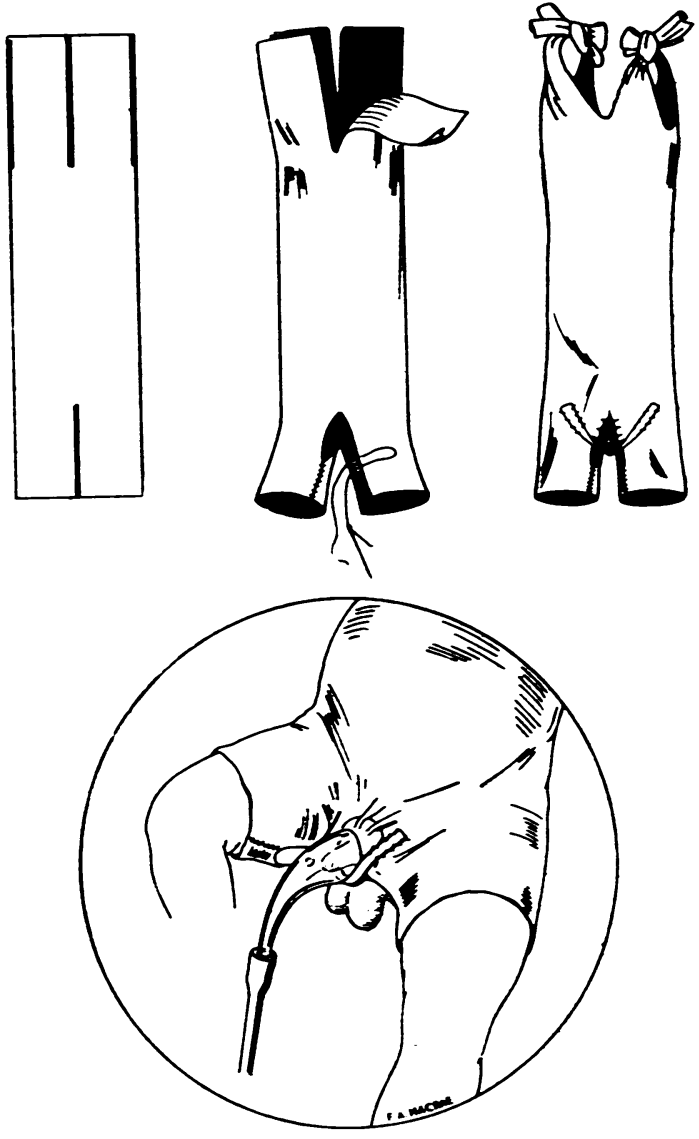

Fig. 3.

in which only the urine was required the following method was eventually devised.

The apparatus consists essentially of a pair of combinations, made out of plaster stockinette, to the front of which is stitched a piece of elastic. This holds a glass tube in position over the penis.

Apparatus for Marasmic and Premature Infants

A piece of plaster stockinette 15 in. long and 4 in. wide is cut down as shown in Fig. 3 (i.e. in two places at 
the lower end and in four at the top, to make 'shoulder straps '). The cut edges on either side of the lower slit are sewn together for 1 in. upwards to form 'legs'. A piece of elastic 2 in. long and $\frac{1}{4}$ in. wide is sewn across the upper part of the slit in front at an angle to the midline, so that the free part in the middle is in a plane at right angles to the rest of the garment. It is as well to stitch round the rest of the hole which is to receive the tube, to give a firmer edge. The tube should be made as in Fig. 2c (considerably smaller, though similar to, that used for the metabolic bed). It is as well to have several sizes, ranging from $12 \mathrm{~mm}$. to $16 \mathrm{~mm}$. diameter. The hole in the 'dorsum' of the tube is very important as it prevents the penis becoming oedematous.

The combinations should be put on first and drawn well up, and knotted or tacked on the shoulders. The slit should be extended upwards at the back, so that the chances of soiling are minimized. The tube is then slipped over the penis and into the hole above the elastic, which should grip the tube firmly below the flange. The lower end of the tube is connected by rubber tubing to a bottle under the cradle.

A triangle of gamgee is wrapped round the child in the usual way, and the point is not brought up between the legs but is left free.

It is important that the mattress should be sloped. This is done by means of a specially made board which slips into the cradle under the mattress and raises the head end. In addition, the head of the cradle is hung from a higher hook at the head end, and a lower at the foot.

The advantages of this method are: (1) The baby is not immobilized in any way. (2) There is nothing to harm the skin, or cause discomfort. (3) The glass urinal can be slipped on and off without removing the combinations, and therefore without having to undress the baby.

This apparatus has been used on premature infants for eight days in succession without loss of urine or trauma.

Recently it has been found that, when using this method on more active healthy full term infants, additional measures are necessary to prevent the baby kicking the tubing off. The simplest and most effective of these is a napkin, put on outside the combinations in the usual way, but with the two points brought up separately in front and pinned one on either side of the tube.

With these methods and modifications we have found it possible to make any collections required, so far, from boys.

\section{Problems of Marking}

There is great variation in the time taken for food to pass through the gut, in different individuals and also in the same individual on different occasions.
It is therefore necessary, when assessing accurately the faeces relevant to a certain period, to mark the beginning and end of the period with some substance which when given orally will be recognizable in the faeces. The most widely used marker seems to be carmine, both in this country and in the United States. This has the advantage of being easily administered but it also has the great disadvantage of spreading within the gut, giving a very indefinite end-point and, in some cases, it apparently causes purgation.

Macy, Reynolds, and Souders (1939) have done an extensive investigation into the use and action of carmine. In a survey of healthy children it was given every fifth day for eight months. As it seemed at times to have a laxative effect, this was investigated. Barium meals containing carmine were given and serial $x$-ray films taken at intervals until the meal had been eliminated. A control series was done without the carmine in the same individuals. In the seven children investigated there seems to have been a remarkable uniformity of response. Although there was considerable ' hurry' through the stomach and upper part of the gut, this was compensated for by a slower passage through the large intestine than the control meal. In every case the entire marker seems to have been excreted in the second defaecation after ingestion and they conclude that no laxative effect was demonstrated. This has not been our experience, as Table 1 will show. This illustrates the results after giving two drachms of liquor carminae $(6 \%)$ to 25 children of varying ages with normal gastro-intestinal function. There is wide variation in response, and extensive 'spreading' in some cases. In case 6 there was definite purgation, the first carmine stool appearing four hours after ingestion and being looser than normal. In the case which was slowest to respond, a further test was made, with a much more rapid result. As there was such a wide variation, it was thought worth while trying to establish where, in the gut, the variation occurred. For this purpose serial films were taken following barium meals (in water) in four normal children (Table 2). In all these the meal was in the colon in nine hours, although the time taken to eliminate the meal varied from 24 hours to six days. In view of this result it was thought probable that the whole meal could be recovered in 24 hours by giving a colonic washout.

Four children were given a barium meal and a film was taken 24 hours later. An enema was then given and another film taken immediately afterwards. In every case the second film showed that very nearly complete elimination had oocurred. Compared with the carmine method, very much greater 
TABuE 1

Results after Giving lguor Carminae (2 dr.) to Chimdren with Normal Gastro-intestinal function

\begin{tabular}{|c|c|c|c|c|}
\hline No. & Age & $\begin{array}{l}\text { First Appearance of Carmine } \\
\text { (in hours) }\end{array}$ & $\begin{array}{l}\text { Other Appearances } \\
\text { (in hours) }\end{array}$ & $\begin{array}{l}\text { Final Appearance } \\
\text { (in hours) }\end{array}$ \\
\hline 1 & $3 / 12$ & 24 & & 263 \\
\hline 2 & $4 / 12$ & $14 \frac{1}{2}$ & 20 & \\
\hline 3 & $5 / 12$ & 15 & & \\
\hline 4 & $9 / 12$ & $14 \frac{1}{4}$ & $17,28,45$ & 48 \\
\hline 5 & 1 & $13 z$ & & $19 \frac{1}{2}$ \\
\hline 6 & 1 & $4 \frac{1}{2}$ & 16 & 40 \\
\hline 7 & $12 / 12$ & 11 & & \\
\hline 8 & $12 / 12$ & 21 & $41 \frac{1}{2}$ & 43 \\
\hline 9 & $14 / 12$ & 17 & $41 \frac{1}{2}$ & 70 \\
\hline 10 & $16 / 12$ & $48 \frac{1}{2}$ & & \\
\hline 11 & 2 & 14 & 23 & 39 \\
\hline 12 & 3 & 19 & & $41 \frac{1}{2}$ \\
\hline 13 & 3 & 41 & & \\
\hline 14 & $3 \frac{1}{2}$ & $18 \frac{1}{2}$ & & 47 \\
\hline 15 & 4 & $46 \frac{1}{2}$ & 63 & 69 \\
\hline 16 & 4 & $15 \frac{1}{2}$ & & 23 \\
\hline 17 & 4 & 13 & $46 \frac{1}{2}$ & 60 \\
\hline 18 & 5 & $42 \frac{1}{2}$ & 69 & 1114 \\
\hline 19 & $5 \frac{1}{2}$ & 15 & $47 \frac{1}{2}$ & $71 \frac{1}{2}$ \\
\hline 20 & 7 & $17 \frac{1}{2}$ & & 41 \\
\hline 21 & 9 & 23 & & 71 \\
\hline 22 & 9 & 51 & & 73 \\
\hline 23 & 10 & 25 & & \\
\hline 24 & 10 & 19 & 110 & 163 \\
\hline 25 & 11 & 120 & 140 & 166 \\
\hline
\end{tabular}

accuracy could be obtained by this means. included, and this must occur either at the beginning Unfortunately, there are two disadvantages: first, the increased discomfort and psychic trauma to the child, and secondly, the enormous amount of drying of the stool required when the colonic washings are or the end of the metabolic period.

Until a better marker is devised, therefore, we are still using carmine. 
TABLE 2

Results of Serial Film showing postron of Barium Meal at Intervals after ingestion

\begin{tabular}{|c|c|c|c|c|c|c|c|c|}
\hline \multirow[b]{2}{*}{ No. } & \multirow[b]{2}{*}{ Age } & \multicolumn{7}{|c|}{ Time Interval (Hours) } \\
\hline & & 9 & 24 & 30 & 48 & 54 & 72 & 78 \\
\hline 1 & 10 & $\begin{array}{l}\text { Round } \\
\text { colon in } \\
\text { rectum }\end{array}$ & $\begin{array}{l}\text { Mostly in } \\
\text { rectum }\end{array}$ & Same & Same & & & \\
\hline 2 & 6 & $\begin{array}{l}\text { Some in } \\
\text { stomach ; } \\
\text { rest in colon }\end{array}$ & $\begin{array}{l}\text { Almost } \\
\text { eliminated }\end{array}$ & & & & & \\
\hline 3 & 6 & All in colon & Pelvic colon & $\begin{array}{l}\text { Mostly } \\
\text { pelvic colon }\end{array}$ & Same & Same & In rectum & Clear in $84 \mathrm{hrs}$. \\
\hline 4 & 7 & In caecum & $\begin{array}{l}\text { Pelvic } \\
\text { colon }\end{array}$ & Same & Rectum & Rectum & & $\begin{array}{l}\text { Some in rectum } \\
\text { at } 98 \text { hours. } \\
\text { Eliminated at } 6 \\
\text { days }\end{array}$ \\
\hline
\end{tabular}

\section{Summary}

A metabolic bed is described, and methods of collecting urine quantitatively from premature and full-term infants.

The advantages and disadvantages of each method are discussed.

An investigation into the efficiency of carmine used as a marker is described.

Acknowledgments and thanks are due to Professor Moncrieff who instigated the work on metabolic apparatus, and to Dr. W. W. Payne who suggested and directed the work on markers; to the Belle Vue Hospital, New York, for the basic idea of the metabolic bed; also to the nursing staff concerned, especially that of the Premature Baby Unit at the Postgraduate Hospital, Hammersmith, for their co-operation and gallant perseverance; and to Mr. D. Martin (Hospital for Sick Children) for the photograph.

\section{REFERENCES}

Bendix, B. (1896). Jhrb. Kinderheilk., 43, 23. , and Finkelstein, H. (1900). Disch. med. Wschr., 26, 672.
Coulson, R. A., and Stewart, C. A. (1946). Proc. Soc. exp. Biol., N.Y., 61, 364.

Dann, M., Marples, E., and Levine, S. Z. (1943). J. clin. Invest., 22, 87.

Du Bois, E. F. (1911). Amer. J. Dis. Child., $2,415$.

Gerstley, J. R. (1930). Ibid., 40, 27.

Gordon, H. H., Levine, S. Z., Wheatley, M. A., and Marples, E. (1937). Ibid., 54, 1030.

Hoag, L. A. (1932). Ibid., 44, 770.

Hoobler, B. R. (1912). Ilbid., 3, 253.

Howland, J., and Cooke, R. A. (1911). Ibid., 2, 419.

Levine, S. Z., Gordon, H. H., and Marples, E. (1941). Ibid., $20,209$.

- Dann, M., and Marples, E. (1943). J. clin. Invest., $22,551$.

Macy, I. G. (1942). "Nutrition and Chemical Growth in Childhood.' Vol. I, p. 104. Baltimore.

—, Reynolds, L., and Souders, H. J. (1939). Amer. J. Physiol., 126, 75.

Schabad, J. A. (1908). Arch. Kinderheilk., 48, 402.

Schloss, O. M., and Crawford, J. L. (1911). Amer. J. Dis. Child., 1, 203.

Talbot, T. B. (1909). J. Amer. med. Ass., 53, 1818.

Thomson, J. (1944). Arch. Dis. Childh., 19, 169. 